\title{
UN NOVÍSIMO ATÍPICO: LA \\ SINGULARIDAD POÉTICA DE \\ MANUEL VÁZQUEZ MONTALBÁN ${ }^{1}$
}

\author{
THE POETIC SINGULARITY OF \\ MANUEL VÁZQUEZ MONTALBÁN
}

Marta Beatriz Ferrari

Universidad Nacional de Mar del Plata

RESUMEN: En el presente artículo intentamos una aproximación crítica a tres libros iniciales de Manuel Vázquez Montalbán —Una educación sentimental, Manifiesto subnormal y Liquidación de restos de serie-, textos de los que proceden los poemas incluidos en la antología de José María Castellet Nueve novísimos poetas españoles. A partir de allí, nos proponemos demostrar el carácter de «novísimo atípico» de Vázquez Montalbán y analizar el lugar fronterizo que ocupa su escritura poética, deudora tanto de las vanguardias como de los poetas sociales, con claras alusiones al contexto histórico y biográfico del autor y a las circunstancias de producción real de su escritura, elecciones todas que desmienten de plano la tan defendida autonomía del lenguaje poético, la negación del carácter referencial y la tautológica y narcisista orientación metapoética que definió a la estética novísima.

Palabras clave:Vázquez Montalbán; antología; poesía social; novísimos.

ABSTRACT: In this article we attempt a critical approach to three early books of Manuel Vázquez Montalbán —Una educación sentimental, Manifiesto subnormal y Liquidación de restos de serie-; most of the poems included in José María Castellet's anthology Nueve novísimos poetas españoles comes from those books. We also intend to demonstrate the singularity of this Spanish author, analyzing the border place of his poetic writing, debtor both avant-garde and social poetry, with a clear reference to historical and biographical context of the author, a Lanz Rivera, de la Universidad del País Vasco. 
choice that denies the defended autonomy of poetic language, the refusal of referentiality and the tautological and narcissistic metapoetic orientation that usually defined the aesthetics of the so called «novísimos».

KeY-Words:Vázquez Montalbán; anthology; social poetry; novísimos.

El juicio de la historia que será el juicio último sobre la obra y su autor ya está encauzado en el juicio del primer lector, $y$ la posteridad deberá tomar en cuenta el sentido público que los contemporáneos le hubiesen legado.

Pierre Bourdieu

La posteridad literaria de un escritor español depende de los textos escolares, de los diccionarios enciclopédicos

$y$ de los departamentos de Hispánicas de las universidades extranjeras. Manuel Vázquez Montalbán

En un artículo del año 2007, Luis García Jambrina señalaba respecto de las antologías de poesía algo que nos sirve para pensar el papel central que jugó Nueve novísimos poetas españoles, de José María Castellet, a la hora de imponer unos determinados nombres y una cierta estética. García Jambrina reconocía que, si bien la influencia de las mismas era grande, su papel no era ni irreversible ni determinante, y como prueba testigo citaba el caso de Antonio Gamoneda, un poeta que, según el autor, por diversas razones, «no comienza a aparecer en antologías hasta fechas recientes, y, sin embargo, ha alcanzado un gran reconocimiento, incluido el Premio Cervantes», y concluía con esta aserción: «Y es que el Tiempo [sic] sigue siendo el mejor antólogo» (García Jambrina, 2007: 20).

Desde 1932, año en que Gerardo Diego publica Poesía española. Antología 1915-1931, libro que canonizara a la llamada «Generación del 27», se suele repetir que la historia de la poesía española del siglo $\mathrm{xx}$ es, en gran medida, la historia de sus antologías, y en esta aceptación se está reconociendo la directa incidencia que el objeto antológico tiene en la conformación de una historia literaria. De 
hecho, el historiador literario y el antólogo operan a partir de un mismo proceso básico, el de la selección, y apuntan a un mismo fin: constituir un canon selectivo. Antología y generación resultan categorías que suelen protegerse y justificarse mutuamente, al hacer depender la selección antológica de un - muchas veces - forzado «decir generacional». Esta íntima trama que liga lo literario a lo histórico llega, en ocasiones, a revestir perfiles emblemáticos, como ocurrió con la antología de José María Castellet. En ella encontramos el ejemplo más claro de cómo cierto período histórico es reconocido todavía hoy por el título de la antología que aglutinó unos nombres determinados, si bien, en la actualidad, ningún crítico o historiador literario reduce esa "generación» a los nueve propuestos por Castellet. Clara muestra de ello es el reciente aporte crítico de Juan José Lanz titulado precisamente Nuevos y novísimos poetas. En la estela del 68 (2011), libro que recoge ensayos sobre escritores como Pedro Gimferrer y Guillermo Carnero, entre los «novísimos» castelletianos, y Diego Jesús Jiménez, Jaime Siles, Luis Alberto de Cuenca y Víctor Botas, entre los «nuevos» poetas.

Sabido es que el rescate o la anonimia, la aceptación o el rechazo, la canonización o no de determinadas obras literarias depende - a pesar de lo que Harold Bloom se empeña en sostener en su polémico ensayo El canon occidental, esto es, la dudosa primacía del valor estético sobre los intereses políticos o económicos- de factores institucionales e ideológicos, es decir, depende, en primera y última instancia, de factores de poder. Al nacer de la negociación y el pacto, «una antología poética — como señala Ruiz Casanova (2007: 22) — no es solo una opción estética, teórica, crítica o literaria, sino que precisamente por serlo es, ante todo, una opción política» ${ }^{2}$.

El antólogo es, a la vez, un ensayista, un crítico, en cierta medida un archilector.Y en este contexto se actualiza la definición que propusiera hace más de veinte años Claudio Guillén:

La antología es una forma colectiva intratextual que supone la reescritura o reelaboración, por parte de un lector, de textos ya existentes mediante su inserción en conjuntos

2 «Lo selectivo — dirá Ruiz Casanova- no es políticamente correcto; es entendido como signo de elitismo, aristocratismo y autoritarismo»; y más adelante agrega: "pues lo que está en juego, en definitiva, son modelos políticos de la escritura, de la lectura, de la crítica, de la edición» $(2007: 24,77)$. 
nuevos. La lectura es su arranque y su destino, puesto que el autor es un lector que se arroga la facultad de dirigir las lecturas de los demás, interviniendo en la recepción de múltiples poetas, modificando el horizonte de expectativas de sus contemporáneos. Escritor de segundo grado, el antólogo es un superlector de primerísimo rango (Guillén, 2005: 375).

Pero vayamos al caso que nos ocupa. Cuando en 1970 Castellet da a conocer, a través de la innovadora editorial barcelonesa Barral, la antología Nueve novísimos poetas españoles, estaba naciendo el primer fenómeno literario íntimamente asociado a la industria cultural de toda la historia de la literatura española. Son muchas y muy conocidas las circunstancias que transformaron esta antología en un acontecimiento tan atípico como polémico.

La aparición de la antología se demoró por conflictos editoriales, y, en el momento de su lanzamiento, ya el grupo se había disuelto. De hecho, Guillermo Carnero se refiere al prólogo de la antología de Castellet señalando que el mismo fue "afortunado en su momento pero cuya putrefacción ha sido rapidísima» (en Luna Borge, 1991: 26), y Leopoldo María Panero confiesa: «La mayoría de los novísimos, si no todos, aprendimos a escribir después de la antología» (ibíd.). De hecho, muchos fueron los poetas que abandonaron rápidamente la causa original y muchos también los que cambiaron de género para intentar la narrativa, el guion cinematográfico o la crítica literaria. En este sentido, el abandono del castellano como lengua poética por parte de Pedro Gimferrer precisamente en 1970 puede ser interpretado como un modo de deserción efectiva de la estética novísima, contribuyendo así a la tesis de Ignacio Prat, para quien «el año fundacional de la antología es también su año funeral» (1982: 43).

El episodio «novísimo» fue un fenómeno, en gran medida, publicitario y con clara pretensión canónica, y contó con fuertes apoyos críticos y editoriales desde Cataluña. Fue una antología netamente metropolitana que, sin embargo, se quiso imponer como representativa de todo el panorama poético español de la década del 70, y, también, una selección que no en todos los casos operó sobre un material previo, como lo demuestran, por ejemplo, Guillermo Carnero y el propio Vázquez Montalbán. Ambos confiesan haber escrito, por encargo del antólogo, poemas ad hoc que no en todos los casos serían posteriormente incorporados a libros 
unitarios. Otro hecho significativo que también desmiente lo que subrayaba Claudio Guillén respecto de las antologías es la inclusión de poetas con obra inédita en libro, como fue el caso de Leopoldo María Panero y de Vicente Molina Foix.

Una de las cuestiones que suscitó inmediata respuesta fue el carácter rupturista que para Castellet definía a estas poéticas, planteo que inducía a pensar en la existencia de un corte en el paradigma poético español hacia finales de la década del 60. Muchas fueron las voces que limitaron el carácter de dicha ruptura. Con su usual estilo irónico, Vázquez Montalbán declaraba en 1988, respecto de la antología castelletiana:

Fue la de los novísimos una línea imaginaria más de las muchas que mal dividen la literatura española, a mayor comodidad de industriales y comerciantes del libro de texto y de investigadores de líneas imaginarias. Se trazó aquella línea como frontera cerrada hacia el capítulo de la reciente poesía social y sin más permisos de importación que cuanto viniera de la generación del 27 más culterana o de lo más culterano del patrimonio poético español. Como corrección de dogma y secta no estuvo mal pero como real decreto del final de nuestra historia poética puede provocar, ya está provocando, un mal final infeliz. Con cuatro parmenidades, unos calzoncillos braga de Oscar Wilde y tres crepúsculos interiores más uno y medio exterior, se ha impuesto una poesía retórica tan bien como previsiblemente escrita, que ni hace ni deja hacer (Vázquez Montalbán, 1988: 29).

La primera vez que el nombre de Manuel Vázquez Montalbán aparece en una antología es en 1967, en la Antología de la joven poesía española de Enrique Martín Pardo. Entre los autores seleccionados figuraban José María Álvarez, Agustín Delgado, Pedro Gimferrer y José Miguel Ullán. Un año más tarde, José Batlló reúne bajo el título Antología de la nueva poesía española a los poetas más representativos de la llamada "generación del 50» —Carlos Barral, Francisco Brines, Eladio Cabañero, Jaime Gil de Biedma, Ángel González, José Ángel Valente, Claudio Rodríguez-, a los que suma algunos de los nuevos nombres que ya habían aparecido en la selección de Martín Pardo, como Pedro Gimferrer y Manuel Vázquez Montalbán. En 1969, el poeta Leopoldo de Luis publica la segunda edición de Poesía social. Antología, en la que aparecen 
los «sociales» propiamente dichos — Gabriel Celaya, José Hierrojuntamente con Vázquez Montalbán. La inclusión de miembros de uno y otro grupo en estas tempranas antologías - auténticos anticipos de Nueve novísimos - habla claramente de la pacífica convivencia de la voz de Vázquez Montalbán junto con la mayoritaria presencia de los poetas del medio siglo. El carácter rupturista que Castellet y sus seguidores le atribuyeran al grupo «novísimo» queda, sin dudas, relativizado.

Sin embargo, será la antología Nueve novísimos la que bautice con un nuevo nombre a este grupo poético. En ella, Vázquez Montalbán figurará entre los seniors, junto con José María Álvarez y Antonio Martínez Sarrión. El escritor catalán participa con diez poemas, cinco de ellos pertenecientes a su libro Una educación sentimental (1967), tres al Manifiesto subnormal (1970) y dos («Yvonne de Carlo» y "Arte poética») compuestos ad hoc para la antología y recogidos luego en esa suerte de apéndice de su primer libro que es Liquidación de restos de serie (1971). A continuación abordaremos esos poemarios iniciales de los que procede la casi totalidad de los textos poéticos presentes en la antología castelletiana.

La mayor y más significativa disidencia que ostenta la poesía de Manuel Vázquez Montalbán respecto de sus compañeros de antología la encontramos en la poética que compone el autor al finalizar la primera edición de Memoria y deseo, en la que leemos: «Durante mi estancia en la cárcel de Lérida en 1962 y 1963 encontré mi primera forma poética satisfactoria [...]. Durante esa estancia carcelaria escribí Una educación sentimental y Movimientos sin éxito» (Vázquez Montalbán, 1986:277). A partir de un contexto de producción semejante, nada de lo que hará el autor responderá de modo ortodoxo a los presupuestos estéticos que plantea Castellet en su prólogo.

Efectivamente, la opción poética del escritor catalán constituye una excepción dentro del culturalismo neomodernista o neobarroco del 68, y así lo reconoce uno de sus críticos, Manuel Rico, cuando afirma: «Una excepción que no renunciaba a las poéticas inmediatamente anteriores, especialmente a la poesía social y a la poética del 50» (2005: 148).Y es que el lugar que ocupa su escritura es un lugar fronterizo, deudor tanto de las vanguardias como de los poetas sociales, algo que podemos comprobar ya en su poemario inicial, con la clara referencia al contexto histórico-biográfico 
del autor. Esta elección desmiente de plano la tan defendida autonomía del lenguaje poético, la negación del carácter referencial y la tautológica y narcisista orientación metapoética que definió a la estética novísima. El propio Castellet afirma: «La poesía de Vázquez Montalbán es, originariamente, autobiográfica», aunque aclara que, como bien señala Philippe Lejeune, «el pacto autobiográfico que se establece entre el autor y la obra (es decir con el lector que rehace la obra) excluye al autor, negándole toda consistencia que no sea literaria» (Castellet, 1986: 15).

En este contexto, no resultaría osado realizar una lectura de su escritura poética a la luz de la llamada «autoficción», noción que nos permite restituir el vínculo obra-autor, apoyándonos en marcas del texto - aparición explícita del nombre de autor, alusiones autobiográficas verificables, remisiones directas a la historia empírica y a las circunstancias de producción real de la escritura- que nos reenvían al contexto autoral. Como se sabe, la ficcionalidad del género lírico es una aserción que se sanciona pragmáticamente, pero, como bien recuerda Lázaro Carreter, decir que «la poesía, la literatura es ficcional» no implica decir "que sea una mentira», algo que reitera Barbara Herrnstein Smith cuando afirma que en poesía «hay ficción pero no hay engaño» (Lázaro Carreter, 1990: 35, 38). En este sentido, coincidimos con Túa Blesa, para quien la calificación de un texto como referencial o como ficcional (también como histórico o como autobiográfico) depende del efecto de lectura. Túa Blesa considera que el error de las teorías de la ficcionalidad es llevar al extremo la imposibilidad de trasvase o intersección entre esas dos series textuales, la referencial y la ficcional, y describe estos movimientos pendulares del poema como una efectiva «salida del texto al universo del archivo", lo que produce en nuestra lectura «un continuo deslizamiento por una banda de Moebius» en la que los textos están en una continua circulación (Blesa, 2000: 44).

Vayamos, entonces, a nuestro primer poemario. Una educación sentimental está compuesto por tres secciones: «El libro de los antepasados», «Una educación sentimental»y «Ars amandi». Como tempranamente advierte Manuel Revuelta, «dividir el libro en tres partes no es arbitrariedad, sino necesidad de una concepción dialéctica» (1967: 456).Volveremos más adelante sobre esta cuestión.

«El libro de los antepasados» nos sitúa cronológicamente en un pasado, el de la infancia del sujeto, que se corresponde con el 
contexto de una España posbélica, claro residuo autobiográfico, ya que el propio Vázquez Montalbán nace el año en que finaliza la Guerra Civil. Asistimos, entonces, a la reconstrucción, a través del ejercicio de la memoria, de esos recuerdos infantiles: «Y papá habló con un marino de bigotes amarillos / en un mercante» $(36)^{3}$, o «ellas llenaban entonces hasta los bordes el plato / del hijo que soñaba imposibles enemigos desconchados / en la pared pintada por la madre / en la primavera / con un cubo de cal y polvos mágicos» (40). En esta misma línea, el poema titulado «SOE» tematiza los recuerdos del niño en la sala de espera del médico del Seguro Obligatorio de Enfermedad: el temor al contagio, el fantasma de la tuberculosis, otro de los males de la posguerra: «los moros, tosía, tosía, el pañuelo, sangre, / las madres nos hacían salir al descansillo, / miraban el aire con temor, dicen que basta el aire» (42). Este sujeto que es, en ocasiones, el «niño» o el «hijo» aparece también como el «alumno», ficcionalizando, una vez más, su referente biográfico, su temprana vocación poética: "Cuando eras una princesa omnipotente / y yo tu juglar de versos vergonzosos» (46). Este poema, titulado "In memoriam», reformula el enigma hamletiano en clave de humor irónico: «tu mano de profesora culta / dividió mi mundo proletario / saber o no saber / la cuestión era aceptar / un blanco destino de burócrata» (ibíd.).

El tono que preside el libro es, en principio, nostálgico; nostalgia de un tiempo definitivamente ido, aquellos «felices tiempos» que evoca el sujeto en la composición inicial. Pero, como es habitual en la escritura del autor, esta nostalgia irá cediendo progresivamente hacia un registro irónico que pretenderá desdramatizar los recuerdos. Lejos de la condensación lírica, estas composiciones primeras optan por la gran extensión y arrojan como resultado poemas narrativos, de desarrollo gradual, en los cuales las escenas se suceden y despliegan paralelamente al acto de lectura; pensado en términos cinematográficos, diríamos que se desarrollan casi en tiempo real. La enunciación - mayoritariamente colectiva- incorpora al sujeto a la experiencia generacional compartida con los otros: «espiábamos / la variación anormal de la chaqueta a cuadros / Príncipe de Gales» (35). Pero la presencia de esos otros no queda

3 La numeración de las páginas corresponde en todos los casos a la siguiente edición: Manuel Vázquez Montalbán, Memoria y deseo (Obra poética 1963-1983), Barcelona, Seix Barral, 1986. 
solo relegada a una indefinida primera persona del plural, sino que tales voces se incorporan al corpus del poema a través de un decir polifónico. En ocasiones es «la voz / del musclaire: / arri Joan que l'arrós / s'está covant» (ibíd.); otras veces es la voz de la madre: «Singer, me inclino por la Singer / cansa menos los riñones» (ibíd.), o las voces corales de las manifestaciones políticas callejeras: «Visca Maciá qu'és catalá, mori Cambó qu'és un cabró» (36).

Pero este descentramiento del espacio enunciante que configura un mundo habitado por una multitud de hablantes no se debe exclusivamente a la incorporación de voces nítidamente individualizadas, sino también - y fundamentalmente - a la inclusión de discursos otros. En este sentido opera la apelación al collage que da cabida al discurso publicitario con su incitación al consumo — «pay-pays de cartón blanco / con anuncios de linimento Sloan» (ibíd.) - y sus slogans turísticos — «Spain is different» (44)—, al discurso radiofónico — «hacia las nueve las emisoras / transmitían un "buenas noches" a la ciudad" (38)—, al discurso periodístico con sus titulares y sus avisos clasificados — «cerró Ingraf / la Sopena precisa obreros para editar / cartillas de abasto, o recaderos Roura / necesita mozos a horas libres» (ibíd.)—, al imaginario cinematográfico y de la canción, con presencias emblemáticas como las de John Gilbert y Greta Garbo o Jean Harlow, Conchita Piquer, Glenn Miller y Bonet de San Pedro, respectivamente (36-39).

La convivencia de esta pluralidad de discursos sociales desplaza funcionalmente al sujeto en tanto originador y controlador de todo el entramado discursivo. La técnica del collage, desde su uso inicial por los pintores cubistas, supuso la inclusión de la materialidad de lo real en la obra artística. Saúl Yurkievich, en su estudio sobre las vanguardias literarias, señala que Apollinaire fue el primero en introducir las técnicas ideográficas, y que al hacerlo "abrió por completo el poema a la intromisión, a la contaminación de los discursos de afuera que irrumpen como representantes de la bulliciosa contextualidad extraliteraria, de la estrepitosa polifonía metropolitana» (Yurkievich, 1984: 62). De este modo, «el poeta cede el privilegio de la autoría a los hablantes anónimos, al coro ciudadano, para que la multivocidad ambiental ocupe el lugar del sujeto lírico, de ese egótico que acostumbra a autoexplayarse monopolizando todas las instancias enunciativas» (ibíd.: 63). 
Por otra parte, el polilingüismo se suma a estos discursos massmediáticos, que se suceden ininterrumpidamente tejiendo una red de mensajes disímiles y, en ocasiones, contradictorios, que abruman al lector a través de la proliferación informativa logrando un efecto alienador ${ }^{4}$. Esta serie de textos contiguos que se influyen mutuamente crean la ilusión de un discurso homogéneo, permitiendo una lectura metonímica, es decir, por contigüidad. Por estos mismos años, el crítico italiano Gillo Dorfles vinculaba ese vasto sector de las artes provocadas y propagadas por los mass media al fenómeno kitsch, y analizaba el doble manejo que posibilitaba esta relación. Por una parte, sostiene Dorfles, puede operarse la degradación de la obra de arte original, pero también - y este es el caso que aquí más nos interesa - esta manipulación permite que «material para-artístico [sea] utilizado con fines decididamente estéticos, como el verso pegadizo y romántico o el estribillo de una canción, hábilmente incluidos en un texto literario" (Dorfles, 1969: 186). Se produce así el rescate o sublimación de materiales que, de entrada, no pertenecían al dominio convencional de lo artístico. El principio operativo, aquí, es el de la descontextualización o la recontextualización novedosa de los materiales, principio que permite, por un lado, una lectura metonímica de esos textos que, aunque disímiles, pasan a formar parte de una misma serie, y, por otro, y como consecuencia de lo anterior, posibilita una formulación sintética de los «opuestos» —el de «síntesis» es un concepto central, sobre el que volveremos más adelante-.

La apelación a cortes bruscos en el hilo expositivo, a saltos tempoespaciales, a la yuxtaposición de imágenes e historias evocadas se expresa gráficamente a través del empleo reiterado del verso quebrado, que es concomitante con la concatenación de imágenes diversas. De este modo, la composición gráfica y espacial del poema actúa a manera de traducción visual.

En la segunda sección, la que da título al libro, comienza a hacerse evidente la existencia de una clara cronología; estamos ante una escritura que historiza la subjetividad. Aquel sujeto infantil

Manuel Martínez Arnaldos (1990) traza la historia del término mass media y ofrece diversos intentos de tipologización de la comunicación humana. En su visión, la «comunicación instrumental» o «de masas» entra dentro de la llamada "comunicación unidireccional», en la cual la transmisión se verifica a través de un medio técnico, de forma unilateral y directa y sin alteración de los papeles comunicativos de emisor y receptor. 
cede su lugar a un sujeto adulto. En varias composiciones, el sujeto textual se identifica ya - si bien irónicamente - con un sector sociocultural, el de los intelectuales: «Insuficientemente dotados / para cosmonautas / elegimos el duro / tobogán de las humanidades» (57). En otras ocasiones, se trata de un «nosotros» amoroso enfrentado - siempre la tensión es dialéctica en Montalbán- a un «ellos» hostil: «todavía creíamos un poco en las cosas / [...] pero a las ocho / y cuarto volvíamos al mundo de ellos» (51). Pero también son numerosas las composiciones focalizadas en una tercera persona del singular. Son precisamente estos poemas los que van definiendo más claramente los términos de una antinomia que irá recubriendo la totalidad del planteamiento poético del libro: la oposición deseo/realidad, ideal/servidumbres cotidianas.

En la sección final, "Ars amandi», el sujeto participa de un juego dialéctico con un «tú» femenino. Este personaje — «y has de volver a casa antes de las doce» (74) - es el mismo de la composición final: «Duérmete corazón prohibido, duérmete / antes de la hora fronteriza de las doce / en que vuelvas a casa sin haber sido / princesa de cuento, amante de novela, / ni feliz» (85). En estas composiciones de índole amorosa, el sujeto — que hasta aquí se había fusionado en un indefinido «nosotros»— surge en su carácter inalienablemente individual. De modo paralelo, la enunciación se torna más elíptica y metafórica y, en consecuencia, los poemas pierden extensión al tiempo que atenúan el tono narrativo de los iniciales.

Como ya se ha dicho, la de Manuel Vázquez Montalbán es una escritura que se abre al contexto de referencia externa al incorporar y tematizar todos y cada uno de sus componentes: desde el sociohistórico hasta el lingüístico-cultural. De aquí que este libro, Una educación sentimental, pueda ser leído como una crónica que recoge, retrata e historiza personajes, usos y costumbres de la España de posguerra. Como señalábamos más arriba, un rasgo evidente de su poesía - que lo distancia de otros compañeros generacionales- es la fuerte presencia del referente histórico. Son numerosas las alusiones a los años de preguerra — -Alfonso XIII borbónico y flemático pasaba / como pasan los reyes, con majestad, / por el ensanche» (35) - , a la guerra unamunianamente calificada de «incivil» — «demasiado próximas las dianas / en los campamentos, / en las trincheras / en las cárceles» (38) - y a los duros años de la posguerra: "cosíamos tristes arreglos de vestidos viejos / para mutilados cuerpos» (37). Sin embargo, para evocar estos recuerdos se 
abandona la nostalgia inicial y se opta por un registro irónico que produce una deflación del tono elevado, y resta dramatismo al relato: «hablaban de un singular compañero de trabajo / míticos seres sin una pierna o llenos de vieja / metralla soportable» (40).

La antinomia se erige como el principio constructivo en su escritura, y la referencia se construye dialécticamente a partir de oposiciones binarias. Este binarismo opera simultáneamente en diversos niveles. Así, la dicotomía tempoespacial conforma dos ámbitos antagónicos; uno originario, material del recuerdo — «Era distinto abril, entonces / había alegría, y rastros de mejillones / en la escollera, canciones / a la orilla del crepúsculo, / pretendientes» (35)—, y otro actual, instalado en el presente de la enunciación: «nada quedó del puerto, / grúas retorcidas, patrulleros hundidos $[\ldots]$, cascotes / de bombas misteriosamente humanizadas, [...] murieron / pretendientes [...] los geranios se agostaron en cenizas amarillas [...], los gitanos perdieron duende, no / cantaban, tosían de noche bajo el relente» (37).

En esta progresión del desencanto juega un papel fundamental el intertexto eliotiano. Me refiero al T. S. Eliot de Four Quartets, donde leemos: «In my begining is my end», y también: «Time present and time past / are perhaps present in time future».Y es precisamente esta idea la que recorre la totalidad de las composiciones del poemario: «ruinas / de esta habitación, no quedará piedra / sobre lirio / ni siquiera miedo a perder algo / porque en nuestro fin empieza todo / lo que de gris ayer vestimos, los días / ordenados, dispuestos como un ejército / pequeño siempre derrotado» (77). La obsesivamente fuerte convicción de que en el presente está el futuro, en la plenitud la decadencia, en la vida la muerte, domina estas composiciones: «destrozarán las botas la alfombra corinto / arrancarán la vida encuadernada en piel de Rusia / en piel humana / estallarán uno por uno los ladrillos» (84).

Otros textos diseñan los términos de la oposición ideal/servidumbres cotidianas. Poemas como el titulado «Buen amor» denuncian, a través de una ironía corrosiva - la metáfora clara de la muerte del amor-, el fracaso de la convención matrimonial: "Amores porque sí, certificados / amarillos en cajas de caoba con flores / esmaltadas, junto al jabón de olor / en cajones de madera repujada, cómodas / donde descansa en paz el ajuar» (59). La realidad cotidiana emerge desprovista de todo encanto — «Nada 
sorprende. ¡Oh! difunta sabiduría del sorprenderse» (54) - y se añora un pasado en el que «todavía era posible algún misterio» (60), al tiempo que se denuncia la irracional tiranía del hábito: «¿quién, / quién no teme perder lo que no ama?» (58), verso que invierte irónicamente aquel de Quevedo: «¿Quién no teme alcanzar lo que desea?».

En esta misma línea podemos leer «Otoño cuarenta». En él, el enfrentamiento cotidianidad/deseo describe un amplio paradigma de opuestos. Por un lado, la rutina del mundo familiar:

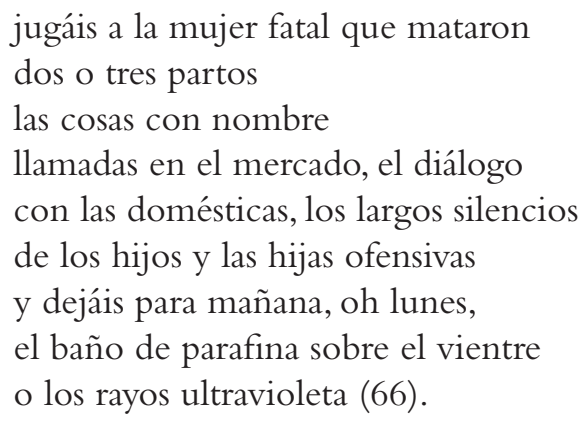

En el extremo opuesto, anhelado, la libertad, la aventura, la impermanencia: "pero llega / exótico, amigo soltero que huele / a lecho individual, sin normas / en la conciencia no entregada nunca / a pasiones constantes» (65), juego de oposiciones deudor del primer Cernuda, cuya síntesis se resume en un solo verso: «no, no es posible el amor, es un sueño romántico» (ibíd.).

Esta trama dialéctica tendiente a desmitificar el amor instituido y legalizado por vía matrimonial adquiere pleno desarrollo en el poema significativamente titulado «Síntesis». En él, la relación amorosa es concebida como una relación de naturaleza eminentemente dialéctica, tesis, antítesis y síntesis: «difícil conciliar el silencio / con la locuacidad de no mediar / la voluntad expresa de una síntesis / cordial» (64). De modo insistente, la escritura de Vázquez Montalbán apunta a desarticular el amplio imaginario que rodea al matrimonio en tanto institución social: «la célula social fundamental / de la comisión cívica democrático-matrimonial» (ibíd.).

Se trata entonces de oponer, al ideal del amor como absoluto, la opción del amor con sus reales limitaciones: «dificil amor sin trastienda / sin despensa ni llave en el ropero» (76). De la sublime aspiración amorosa solo queda para el sujeto «agradecer la soledad 
que me has quitado / que te he quitado» (77). Lo que esta escritura parece rechazar es la formulación literaria del tópico amoroso que disfraza el lenguaje del cuerpo con tropos retóricos: «Tápate las metáforas / sí, cubro yo también mis imágenes impacientes» (75). La ironía emerge como el instrumento más apto para resemantizar esos clichés pretendidamente eróticos: «mientras / haya crepúsculos te amaré, mientras haya poesía te amaré / mientras haya hortensias / te amaré, Hortensia» (76). Pero no solo Bécquer y Ovidio están aludidos en estos versos, también los intertextos quevedianos — «nadie presiente un final adverso / la muerte / será ceniza mas tendrá sentido, polvo / será mas polvo enamorado» (81) - operan a modo de contrapunto; la esperanza del amor redentor, salvador de la muerte, contrasta violentamente con la reflexión de carácter terminal que articulan estos poemas: «será la muerte un papel / amarillo que flota un instante / en la ventana [...]. Olvidable la muerte de todos» (83).

Sostiene Gillo Dorfles que algunos críticos «asimilan al kitsch con el sentimentalismo" y define a este como un pathos privado de todo componente racional, volcado a un regodeo hedonista de sus experiencias: complacencia dulzona frente a elementos de falsa dramaticidad, frente a motivos tristes o macabros o lacrimosos aceptados por su patetismo y no por su efectiva urgencia creativa. El kitsch, según Dorfles (1969:190), transforma las experiencias humanas límites - muerte, nacimiento, sexo, guerra - en episodios patéticos y sustituye las grandes pasiones humanas mediante azucaradas deformaciones sentimentales. Vázquez Montalbán parece ironizar sobre el kitsch así entendido al resemantizar los clichés romántico-sentimentales. Entraríamos, entonces, dentro del llamado kitsch del kitsch en tanto estrategia paródica de la imitación.

Diríamos con Hugo Friedrich que esta poesía se inscribe claramente dentro de la dialéctica de la modernidad. Su escritura tematiza reiteradamente los componentes más degradados de una modernidad urbana: «cercano al trajín del barrio colector / del tráfico de camiones desvencijados, / topolinos grises como de fieltro, el carro / verde del basurero» (38). Como contraparte, los elementos del orden natural se reducen a desvirtuados exponentes de una naturaleza enferma: «rodajas de cielo / pieles de plátanos / deshabitados, mondas de naranja / brutalmente desnudas» (74). En el desarrollo de estos poemas se van alternando las visiones presentes del paseante por un escenario urbano — «el Bar Moderno», «el mal 
llamado Bar de las Putas Francesas», «el Cine Edén»—y las reminiscencias libremente convocadas por la memoria.

Vázquez Montalbán tematiza asimismo la idea del viaje como sinónimo de huida de ese "pequeño planeta de hojas muertas» (75) a que ha quedado reducido el mundo para el hombre moderno. Es el viaje hacia tierras lejanas, hacia paraísos prometidos: «ya tarde, cuando los veleros / mienten puertos ansiados» (58). Pero el sujeto que se construye en estos poemas, invirtiendo la lectura del mito clásico, es un Ulises moderno que descree del futuro y postula la inmanencia en el orden del deseo: «Y quizá todo sea mejor, así / esperado / porque al llegar no puedes volver / a Ítaca, lejana y sola, ya no tan sola, / ya paisaje que habitas y usurpas, nunca» (79).

El segundo poemario del que proceden los textos antologados por Castellet es, como señalábamos anteriormente, Liquidación de restos de serie, título que alude a la reunión de un material heterogéneo disperso, cuyo valor, en tanto mercadería de consumo, está a la baja. La asimilación del texto poético a una mercancía de uso y consumo nos instala claramente ante una concepción de la escritura que, lejos de posicionarla jerárquicamente respecto del resto de las creaciones simbólicas, la equipara con un material descartable. En este sentido, el objeto estético se despoja inmediatamente de su poder aurático. Recordemos que, para Walter Benjamin, cuando la obra de arte entra en relación con las técnicas masivas de reproducción, es precisamente cuando el aura se destruye.

Se trata de un libro de composición disímil y contradictoria que apunta a desdibujar las fronteras genéricas y apela a constantes juegos intertextuales. Voces de diversa procedencia (letras de canciones populares, graffitis callejeros, fórmulas latinas) sumadas al polilingüismo de estos poemas (versos en inglés, francés, catalán) acentúan la heterogeneidad constitutiva y la aparente orfandad enunciativa de los mismos. Esta disparidad de registros pasa a formar parte de un texto en el que cohabitan personajes del cómic (Superman), de series televisivas (James Bond), de cuentos infantiles (Aladino, Alí Babá) con mitos del cine hollywoodense (Yvonne de Carlo, Peter Lawnford), Bach y el tango, Mallarmé y Scott Fitzgerald.

En estos poemas se denuncia, por un lado, el lento pero constante proceso de colonización cultural — «Es este el paraíso / de los muñecos de cartón / los presidentes / de los EE. UU. y los relojes 
/ divididos en cuatro tiempos / en el laberinto de Superman» (104) - y, por otro, la ilusión que diariamente nos vende la sociedad de consumo, esas «mercancías de felicidad». Enric Bou definía los mitos de los años 60 por oposición al mito clásico, y señalaba respecto de aquellos:

El mito cobra aquí un sentido más evasivo [...]. Estos nuevos mitos, desde una aparente frivolidad, fueron una manera de conectar con todos los mitos que compartía una generación del planeta y señalan el comienzo de una cultura uniformizada y más sincrética en la que lo literario (textual, escrito) empezó a quedar relegado a un segundo plano y tuvo ya que empezar a competir con lo audiovisual (Bou, 1992: 191).

El texto poético deja así de poseer un valor autónomo, intrínseco e indelegable para pasar a someterse a las implacables leyes del mercado. A través de la ironía, Montalbán intenta refutar la idea — sustentada por los pragmáticos de la posmodernidad — de que el arte debe ser útil, eficiente y económicamente rendidor. A partir de determinados clichés socialmente legitimados, el autor articula un discurso poético en el que exhibe y desarrolla la metáfora central de su libro: la equiparación de la incipiente sociedad de consumo — los años 60 en España - con una gran Maquinaria: la ilusión de que existe una fórmula — un instructivo - para alcanzar el éxito, y que la existencia no es otra cosa que una desenfrenada carrera hacia esta meta. El poema «¡No corras papá!» emplea un lenguaje técnico-mecánico deliberadamente especializado: «eje rotor», «tapa del distribuidor», "patín del ruptor», «electrodos», «cojinete de empuje», «forros de embrague», y al hacerlo postula un concepto más abarcador de lo poético, idea que lo emparenta con los poetas sociales al concebir la poesía como un manual de instrucción, discurso que roza con el antipoema.

Quizá la forma extrema de elisión del sujeto poético sean las «Visualizaciones sinópticas». Este extenso poema visual, de libre disposición gráfica sobre el blanco de la página, recurre a la estructura de los cuadros sinópticos — concepto con el cual se juega fonética, gráfica y semánticamente- en un intento por reducir al máximo las convenciones del discurso poético. Lo que estos poemas proponen es una nueva lógica discursiva que rehúye los encadenamientos causa-efecto y apela a las asociaciones sorprendentes, 
a los juegos de palabras, a las fórmulas matemáticas, para postular una contralógica fragmentaria. La síntesis de todas esas estructuras binarias que componen el texto es la ficcionalización del propio Manuel Vázquez Montalbán, autonominado en el final del poema, auténtica síntesis cultural entre su educación académica y su posterior formación como burgués consumista:

Instituto de
Cultura
Hispánica
\[ \begin{array}{l}\text { Manuel } \\ \text { Vásques } \\ \text { Montalbá }\end{array} \]

Club de

Fútbol

Barcelona (112).

Efectivamente, Vázquez Montalbán ha insistido en el carácter híbrido de su formación, síntesis de su flaubertiana «educación sentimental» y su «educación académica»:

[mi poesía] es una expresión de mis experiencias vivida en plena dualidad entre mi formación humana dentro de la cultura proletaria y mi formación intelectual en la Universidad y los cenáculos de intelectuales progresistas. Todo esto unido a mi perplejidad posterior de burgués consumista (en Provencio, 1988: 14).

Y, en otras oportunidades, ha brindado mayores precisiones acerca de esta hibridez cultural: "Toda mi poesía es inexplicable si no se tiene en cuenta el mestizaje cultural que asumo en el doble plano de la cultura pop (es decir, popular de masas) y la cultura académica convencional que aprendí en los libros apellidados y en la Universidad» (ibíd.: 23-24). En este acto de apostar por la hibridez reside la opción más clara frente al planteamiento radicalmente dialéctico que exhibe la escritura de nuestro autor. La alternativa de la síntesis que este mestizaje cultural supone nos habilita para considerarlo como una fuerza revolucionaria, capaz de disolver las fronteras que tradicionalmente enfrentaban a la «Alta Cultura» canonizada y al arte popular. Sentado esto, podemos fácilmente vincular el empleo masivo de la técnica del collage con este deseo de síntesis que moviliza el discurso poético. Su escritura se abre de tal 
modo a lo circundante que neutraliza toda frontera entre lo artístico y lo extraartístico. El uso del collage supone, entonces, enfrentarse a la totalidad de la tradición literaria occidental en un intento por fusionar los contrarios, en un afán de síntesis dialéctica en la cual lo culto convive con lo popular, lo académico con lo masivo, lo consagrado con los productos impuestos por la cultura de masas. En este sentido, el autor declara:

Tampoco mi collage cultural es equiparable al de otros poetas de los ya viejos novísimos que Castellet reunió en su escandalosa antología. El collage cultural de Gimferrer es fundamentalmente iconográfico, aséptico, como lo había sido en Pound o en Eliot. En Panero era la enunciación del caos, la declaración de la imposibilidad de ordenar ese puñado de imágenes rotas sobre las que inevitablemente cae la noche. En mi caso era la confesión de mi propia arqueología sentimental, de las ruinas que hay en uno mismo, de las ruinas que hay en todo lo nuevo, en todo lo contemporáneo (ibíd.: 24).

Montalbán deslinda así claramente el empleo meramente visual o sígnico del uso cargado de implicancias ideológicas que preside esta búsqueda de síntesis cultural, de real convivencia de opuestos que exhibe su escritura.

Luego de este rápido recorrido por la inicial obra poética montalbaniana, intentaremos ir delineando algunas conclusiones vinculadas con la inclusión de nuestro poeta en la antología de Castellet. Como hemos podido comprobar, Vázquez Montalbán es un «novísimo» atípico, singularidad que el propio antólogo tuvo que reconocer al afirmar que sus ideas coincidían «solo parcialmente con las de los poetas de su generación» (Castellet, 1970: 26) ${ }^{5}$. En este sentido, los poetas seniors constituirían una promoción intermedia, de tránsito entre los del medio siglo y la veta más rupturista en

5 Juan José Lanz sostiene que «la poesía de Vázquez Montalbán nacía con una voluntad de crónica y crítica semejante a la que habían desarrollado los poetas de la generación inmediatamente precedente (Ángel González y Jaime Gil de Biedma), pero llevando a cabo una profunda renovación formal, en una aspiración a realizar un retrato más ajustado de la sociedad del momento» (2000: 337). También Ángel Otero-Blanco subraya este carácter sincrético de su poesía: «Leer a Vázquez Montalbán equivale a contemplar el equilibrio discursivo entre estética novísima y literatura social, tradición y (pos)modernidad, lírica y narrativa, ensayo y periodismo, pasado emocional y memoria colectiva, pasión y convención, individuo y sociedad» (2009: 74). 
términos estéticos promulgada por la coqueluche, distinción esta que el mismo antólogo reconoce como "forzada», y que justifica como «un grave error», producto de que Nueve novísimos no fue desde el comienzo una antología unitaria sino «el aborto de dos» (Castellet, 1986: 9). De hecho, a partir de la selección castelletiana, el nombre de Vázquez Montalbán desaparece de las antologías sucesivas de Martín Pardo, Nueva poesía española (1970), y de Antonio Prieto, Espejo del amor y de la muerte. Antología de la poesía española última (1971), así como de la de Rosa María Pereda y Concepción G. Moral, Joven poesía española (1979).

Resulta evidente que Vázquez Montalbán, quien se reconocía «como una prolongación de la que se ha llamado poesía social» (Otero-Blanco, 2009: 59), se propuso redefinir este concepto postulando una noción más abarcadora del fenómeno en la que cabe, naturalmente, su propia poesía, en línea con los poetas del 40 y del 50:

Social es todo tipo de poesía y todo tipo de comunicación cultural. Hay poesía muy social: las letras que ha cantado Antonio Machín, por ejemplo, o las de Conchita Piquer, Juanita Reina, Valderrama, etc. Hay poesía un poco menos social: la de Rafael de León, José Carlos de Luna, etc. Hay poesía muy poco social: la de Celaya, Blas de Otero, José Agustín Goytisolo, la mía, etc. Es más social la poesía más sociable, que llega, objetivamente, a más gente. Es menos social la menos sociable, la que solo leemos unos 2500 españoles (en De Luis, 1969: 435-436).

El gesto desencantado que exhibe frecuentemente su práctica poética se debe, en parte, a la constatación de que la poesía actual transita por un circuito restringido frente al alcance masivo logrado por los medios de comunicación. Desde su Manifiesto subnormal, el autor responsabiliza a instituciones y a políticos por «la destrucción de la conciencia reflexiva del pueblo mediante los bisturíes eugenésicos de los mass media» (26). Y advierte con enorme lucidez la distancia que separa a los poetas sociales del 40, con su inquebrantable fe en el poder de la palabra, de los escritores que los sucedieron:

Creo que entre los actuales poetas y los que se inventaron la «poesía social» media un hecho fundamental: la 
comprensión de que los géneros literarios, y sobre todo la poesía leída, han perdido importancia en la conformación de la conciencia pública. ¿Qué puede hacer un poema del mismísimo Blas de Otero con una circulación de mil o dos mil ejemplares frente a programaciones de TV como el viaje del Apolo VIII, que llegan a 700 u 800 millones de seres? ¿Qué puede hacer la literatura política, elíptica en su expresión, frente a una cultura de masas dirigida desde la enseñanza primaria y recocida a través de medios informativos cada vez más alienantes? (ibíd.: 436).

En el año 1952, en la España franquista, el editor y antólogo Francisco Ribes publicaba unas declaraciones que se convertirían más tarde en el slogan de la poesía llamada social. Me refiero a la poética con que Gabriel Celaya, haciéndose eco de los reclamos nerudianos de Caballo verde para la poesía, presentaba sus poemas en la célebre Antología consultada:

La Poesía no es un fin en sí. La Poesía es un instrumento, entre nosotros, para transformar el mundo. [...] En el poema debe haber barro [...]. Debe haber ideas [...]. Debe haber calor animal.Y debe haber retórica, descripción, argumento, y hasta política. [...] La Poesía no es neutral [...]. Y nada me parece tan importante en la lírica reciente como ese desentenderse de las minorías y, siempre de espaldas a la pequeña burguesía semiculta, ese buscar contacto con unas desatendidas capas sociales que golpean urgentemente nuestra conciencia llamando a vida (en Ribes, 1952: 44-46).

Inserta por vocación en la polémica en torno al compromiso artístico, la escritura de Vázquez Montalbán ostenta el gesto desencantado de quien ya no comparte la vieja fe en el poder de las palabras. Escribir ya no es actuar; las palabras dejaron de ser actos. En 1965, Jean Paul Sartre acabaría reconociendo: «La náusea, frente a un niño que se muere de hambre, no tiene poder. No tiene peso alguno, no sirve para nada» (en Vargas Llosa, 2001: 68); en el mismo año, Manuel Vázquez Montalbán afirmaba:

Creo que la poesía, tal como está organizada la cultura, no sirve para nada. Sospecho que no sirve para nada en ninguna parte. [...] Creo que escribir es un ejercicio gratuito que satisface las necesidades de unos 2000 culturalizados progresistas (en Provencio, 1988: 19), 
convicción que reiteraría varios años después en unos versos cargados de implacable ironía: «mientras la Ciencia / del alma / calcula cómo calcular lo incalculable / por ejemplo / cuántos deben morir cada día en Etiopía / para que nos salga social / de pronto / la poesía» (Vázquez Montalbán, 1990: 48).

La aceptación de la inviabilidad de la poesía como instrumento redentor o meramente transformador, con poder real de operación sobre el mundo lleva a Vázquez Montalbán a afirmar:

Claro que esta lucidez obliga a que el compromiso revolucionario del escritor no pueda disfrazarse de literatura. Hay campos de acción cívica para el que quiera encontrarlos; campos más amplios y duros que la soledad de una mesa con una cuartilla blanca dispuesta para la violación» (en De Luis, 1969: 436-437) .

A pesar de la lúcida e inquietante duda (o precisamente por ella), los diversos modos con que Vázquez Montalbán ejerce su ineludible compromiso como escritor, a través de su insobornable conciencia crítica, adquieren siempre la forma de una reflexión ideológica sobre la poesía, y, en última instancia, vienen a insistir en la pregunta que, por esos mismos años, formulara Julio Cortázar, en Rayuela: «Si la lucidez desemboca en la inacción, ¿no se vuelve sospechosa, no encubre una forma particularmente diabólica de ceguera?» (Cortázar, 1968: 261). Toda la obra de Manuel Vázquez Montalbán (la periodística, la poética, la narrativa, la ensayística) no hace otra cosa que dar cuenta de esto mismo; su obra es un combate contra esta lucidez inmovilizadora a la que el hombre está expuesto, evitando la complicidad que encuentra sus justificaciones posmodernas en el fin de las ideologías y la muerte de las utopías, en el conformismo individualista y en la apatía de los acomodados.

6 En otras ocasiones se ha referido a esto mismo calificándolo de ridiculismo: «ismo en el que se incurre cuando el poeta confunde su estilográfica con un proyectil dirigido o su subjetividad con la energía nuclear» (en De Luis, 1969: 436). 


\section{BIBLIOGRAFÍA}

Blesa, Túa (2000). «Circulaciones», en Poesía histórica y (auto)biográfica (1975-1999), eds. José Romera Castillo y Francisco Gutiérrez Carbajo, Madrid,Visor, pp. 41-52.

Bou, Enric (1992). «Sobre mitologías (a propósito de los Novísimos)», en Mythopoiesis: Literatura, totalidad, ideología, ed. Joan Ramon Resina, Barcelona, Anthropos, pp. 191-200.

Castellet, José María (1970). Nueve novísimos poetas españoles, Barcelona, Barral Editores. - (1986). Introducción a Manuel Vázquez Montalbán, Memoria y deseo (Obra poética 1963-1983), Barcelona, Seix Barral, pp. 7-28.

Cortázar, Julio (1968). Rayuela, Buenos Aires, Sudamericana.

De Luis, Leopoldo (1969). Poesía social. Antología (1939-1968), Madrid, Alfaguara.

Dorfles, Gillo (1969). «Kitsch y cultura», en Nuevos ritos, nuevos mitos, Barcelona, Lumen, pp. 180-190.

García Jambrina, Luis (2007). «En busca del canon poético», suplemento «ABCD las Artes y las Letras», $A B C, 5$ de mayo, p. 20.

Guillén, Claudio (2005). Entre lo uno y lo diverso. Introducción a la literatura comparada (Ayer y hoy), Barcelona, Tusquets.

LANZ, Juan José (2000), Introducción al estudio de la generación poética española de 1968. Elementos para la elaboración de un marco histórico-crítico en el período 1962-1977, Bilbao, Universidad del País Vasco.

- (2002a). "Himnos del tiempo de las barricadas": sobre el compromiso en los poetas novísimos», Ínsula, 671-672, noviembre-diciembre, pp. 8-13.

- (2002b). «Poesía y compromiso en la generación del 68. La renovación estética de los sesenta y el compromiso poético en tres poetas: Agustín Delgado, Manuel Vázquez Montalbán y José-Miguel Ullán», en Leer y entender la poesía: conciencia y compromiso poéticos, coords. Martín Muelas Herraiz y Juan José Gómez Brihuega, Cuenca, Ediciones de la Universidad de Castilla-La Mancha, pp. 165-219.

- (2011). Nuevos y novísimos poetas. En la estela del 68, Sevilla, Renacimiento.

Lázaro Carreter, Fernando (1990). De poética y poéticas, Madrid, Cátedra.

Luna Borge, José (1991). La generación poética del 70, Sevilla, Quásyeditorial.

Martínez Arnaldos, Manuel (1990). Lenguaje, texto y mass-media.

Aproximación a una encrucijada. Murcia, Universidad de Murcia. 
Otero-Blanco, Ángel (2009). «Poesía novísima y social en Manuel Vázquez Montalbán», en (En)claves de la Transición. Una visión de los Novísimos. Prosa, poesía, ensayo, eds. Enric Bou y Elide Pittarello, Madrid-Frankfurt, Iberoamericana-Vervuert, pp. 55-77.

Prat, Ignacio (1982). Contra ti (notas de un contemporáneo de los novísimos), Granada, Don Quijote.

Provencio, Pedro (1988). Poéticas españolas contemporáneas.

La generación del 70, Madrid, Hiperión.

Revuelta, Manuel (1967). «Manuel Vázquez Montalbán. Una educación

sentimental», Cuadernos Hispanoamericanos, 215, pp. 456-462.

Ribes, Francisco (1952). Antología consultada de la joven poesía española, Santander, Taller de Artes Gráficas de los Hermanos Bedia.

Rico, Manuel (2005). «La poesía de Vázquez Montalbán», en Leer y entender la poesía: poesía y poder, coords. Martín Muelas Herraiz y Juan José Gómez Brihuega, Cuenca, Ediciones de la Universidad de Castilla-La Mancha, pp. 147-161.

Ruiz Casanova, José Francisco (2007). Anthologos: poética de la antología poética, Madrid, Cátedra.

Vargas Llosa, Mario (2001). Literatura y política, México, Ariel.

VÁzquez Montalbán, Manuel (1970). Manifiesto subnormal, Barcelona, Kairós.

- (1986). Memoria y deseo (Obra poética 1963-1983), Barcelona, Seix Barral.

— (1988). «Por un estado de la pluralidad poética», Taifa, 1, enero, pp. 27-30.

- (1990). Pero el viajero que huye, Madrid,Visor.

Yurkievich, Saúl (1984). A través de la trama. Sobre vanguardias literarias y otras concomitancias, Barcelona, Muchnik Editores. 